\title{
CIRCUITOS DA ECONOMIA URBANA \\ E ECONOMIA DOS SETORES \\ POPULARES NA FRONTEIRA \\ AMAZÔNICA: O CENÁRIO ATUAL \\ NO SUDESTE DO PARÁ 1
}

\author{
Harley Silva \\ Sibelle Diniz \\ VANESSA FERREIRA
}

R E S U M O Embora a expansão do mercado trabalho formal seja uma tendência sustentada no Brasil nos últimos anos, a persistência de formas de ocupação ligadas ao circuito inferior da economia é uma realidade ampla e mal compreendida. Isso é particularmente verdade para as diversas fronteiras da Amazônia brasileira, onde a economia informal, popular, solidária e familiar persiste, a despeito dos grandes investimentos destinados ao circuito superior. Esse trabalho investiga a situação vigente no sudeste paraense, onde a economia formal de alguns municipios tem crescido a "taxas chinesas" e ao mesmo tempo há a presença massiva de formas alternativas de inserção econômica da população, particularmente a de baixa renda.

P A L A V R A S - C H A V E economia dos setores populares; economia informal; circuito inferior; fronteira amazônica; sudeste paraense.

\section{INTRODUÇÃO}

Embora a expansão do mercado de trabalho formal seja uma tendência sustentada no Brasil nos últimos anos, a persistência de formas de ocupaçáo ligadas ao circuito inferior da economia é uma realidade ampla e pouco compreendida. Isso é particularmente verdade para as diversas fronteiras da Amazônia brasileira, onde a economia informal, popular, solidária e familiar persiste, a despeito dos grandes investimentos destinados ao circuito superior.

Este trabalho propóe uma discussão dessas formas alternativas de produção, investigando tal cenário no sudeste do estado do Pará, onde a economia formal de alguns municípios tem crescido a "taxas chinesas" e ao mesmo tempo persiste a presença massiva de formas de inserção econômica fora do mercado de trabalho formal para grande parte da população, particularmente a de baixa renda.

Parte-se da discussão clássica dos circuitos da economia urbana proposta por Santos (1979), aproximando-a das relaçōes entre urbanização e mercado de trabalho nas fronteiras da Amazônia contemporânea. As fronteiras de terras e recursos conferiram historicamente um significado peculiar às relaçôes econômicas em geral e às de trabalho

\begin{abstract}
1 Este trabalho foi produzido a partir das discussões e trabalhos de campo vinculados ao projeto "Urbis Amazônia: qual a natureza do urbano na Amazônia contemporânea?", financiado pelo ITV-DS - Instituto Tecnológico Vale - Desenvolvimento Sustentável - e pela Fundação Vale através de convênio estabelecido com a FUNCATE - Fundação de Ciência, Aplicações e Tecnologia Espaciais. Os autores agradecem à instituição financiadora e aos demais colegas do Urbis pelas contribuições.
\end{abstract}


em particular na Amazônia (COSTA, 2012a). No cenário atual de crescimento econômico, nessa regiáo impulsionado e moldado pela atividade mineradora, cabe indagar uma vez mais o significado da trajetória histórica das fronteiras do Norte do país e suas transformaçôes contemporâneas.

O recurso à visão dos dois circuitos abre também espaço para a discussão do processo de urbanização contemporânea na região. Surge como um desdobramento da dinâmica econômica, mas também como seu suporte e uma das formas de seu enraizamento na região. Nessa via, assumimos a perspectiva da urbanização extensiva (MONTE-MÓR, 1994), chave para uma abordagem compreensiva das dinâmicas da cidade e de seu entorno: seus efeitos desagregadores/integradores do urbano como espaço físico da emancipaçáo material e suporte da vida política, todos estes aspectos particularmente cruciais no contexto amazônico.

Além de dados secundários, são empregadas informaçóes colhidas em trabalho de campo realizado pelos autores em julho de 2012.

\section{DESENVOLVIMENTO, CIRCUITOS DA ECONOMIA URBANA E MERCADO DE TRABALHO NA AMAZÔNIA}

Quinhentos anos após o início do processo de incorporação dessa região à dinâmica da economia capitalista, a Amazônia permanece como uma das fronteiras do planeta. Fronteira de recursos, de conhecimento novo, de possibilidades de construção de um novo padrão de desenvolvimento. A potência do novo na Amazônia ainda náo emergiu de fato, em parte devido ao próprio padrão de incorporaçáo que a regiáo experimentou desde a chegada do colonizador e que se prolongou na história brasileira. Esta se baseou numa ocupaçáo para a retirada de recursos, exportadora de matériaprima. Operou, portanto, "segundo o paradigma sociedade-natureza denominado 'economia de fronteira', em que o crescimento econômico é visto como progresso linear e infinito através da incorporação de terra e produtos naturais percebidos igualmente como inesgotáveis" (BECKER, 2005, p. 401).

A Amazônia brasileira se construiu voltada para fora, como espaço derivado (SANTOS, 2009), "ocupada e povoada em surtos associados às grandes inovaçôes da expansão da economia-mundo" (BECKER, 2009). Conectada a impulsos do novo que não partiram de dentro, mas de fora, como de resto tem sido a trajetória do crescimento com dependência da sociedade brasileira, a regiáo, talvez ainda mais que

2 Conceito devido ao economista chileno Aníbal Pinto Santa Cruz. Refere-se à coexistência e interdependência de setores, em sociedades subdesenvolvidas, de estrutura produtiva e ocupacional díspar. Ver Rodríguez (2006). o restante do país, chama a atenção por sua heterogeneidade estrutural. ${ }^{2}$

Para além de dualidades, a sociedade amazônica é heterogênea. Marcada simultaneamente por experiências da chegada e da busca do novo. Um novo que procura formas no patrimônio desconhecido da biodiversidade local e no conhecimento que lhe corresponde, parte dele detido, ironicamente, por aqueles que são rotulados como os povos tradicionais. Marcada pela recorrente chegada do moderno que, ao se instalar de fora, ignora o novo que ali já reside, e se realiza combinado ao arcaico que traz em si e que encontra.

Essa constante renovaçáo e conservação ganha concretude nas realidades paradoxais da Amazônia. Floresta urbana; cidades da selva; riqueza de biodiversidade a reduzir- 
se em matéria-prima genérica e terra arrasada qualquer; promessa de emancipação a realizar-se como subdesenvolvimento recorrente. Em parte os paradoxos são realidades dissimuladas, não decifradas. Complexidade que se apresenta como transparência no absurdo. Desafios do desenvolvimento brasileiro, que se apresentando como carentes de lógica passam à margem do enfrentamento; aquele que desvendando relaçóes e determinantes os traria a um saber e a uma prática ainda náo construídos, mas que forneceriam soluçóes reais.

Essa heterogeneidade paradoxal pode ser encontrada em um mercado de trabalho cindido pelo que Milton Santos denominou os dois circuitos da economia urbana. Ela também se revela no caráter simultaneamente fragmentado e interligado (LEFEBVRE, 2008) do espaço amazônico com um todo, para além das cidades e dos fluxos econômicos apenas. É assim a urbanização presente em todos os espaços, mas que ao mesmo tempo compóe cadeias produtivas e fluxos fragmentados.

Milton Santos (1979), em sua análise do 'espaço dividido' nos países subdesenvolvidos, aponta para a existência, nas cidades desses países, de dois circuitos econômicos. A configuraçáo dos circuitos tem origem nos processos de industrialização e de modernização vivenciados nesses países, guiados por firmas multinacionais intensivas em tecnologia e geradoras de um número limitado de empregos. Como resultado de tais processos, formam-se dois circuitos. $\mathrm{O}$ superior, altamente beneficiado pelo processo de modernização; o outro, inferior, que parcial ou absolutamente não se beneficia do progresso técnico, do avanço organizacional e das vantagens a eles relacionadas.

A presença de uma massa populacional com salários muito baixos, dependendo de trabalho ocasional para viver, ao lado de uma minoria com altos salários, cria na sociedade urbana uma distinção entre os que têm permanente acesso aos bens e serviços oferecidos e os que, mesmo apresentando necessidades similares, não podem satisfazê-las. Isso cria ao mesmo tempo diferenças qualitativas e quantitativas de consumo. Essas diferenças são, ambas, causa e efeito da existência, isto é, da criação ou manutenção, nestas cidades, de dois sistemas de fluxo que afetam a fabricação, a distribuição e o consumo de bens e serviços. (SANTOS, 2008, p. 95).

No circuito superior, os negócios bancários, comércio e indústria para exportação. A indústria urbana moderna, comércio e serviços modernos, comércio atacadista e transporte. Caracteriza-se por atividades capital-intensivas, mas quase unicamente imitativas ou avessas à inovação. Produção em grande escala, articulada para fora da cidade e da regiáo, tendo como objetivo principal a acumulação de capital. No circuito inferior, atividades intensivas em trabalho, produção em pequena escala e, em certo paradoxo, grande potencial criativo. Forte articulaçáo à vida local, à cidade e à região, possuindo como objetivo primordial "sobreviver e assegurar a vida familiar diária, bem como participar, o quanto possível, de certas formas de consumo peculiares ao moderno modo de vida" (SANTOS, 2008, p. 102). Compóe-se basicamente de serviços não modernos, abastecidos pelo comércio em pequena escala.

Longe de serem realidades estanques, os dois sistemas de fluxos da economia urbana estão em relação permanente, ainda que truncada e seletiva. São relaçóes determinadas por condiçóes históricas gerais, especialmente ligadas à forma de penetração das atividades modernas no território, e pela ação do Estado, que atua como 
3 Distinção estabelecida por Costa (2012b) entre extrativismo de coleta e extrativismo de aniquilamento. Enquanto o último trilha o caminho da anulação do ecossistema original na medida em que toma suas partes como estoque de matéria-prima, o primeiro se estrutura como valores que se retiram de um fluxo cuja lucratividade derivada no mercado depende da sua continuidade, portanto da existência de uma natureza viva que se reproduz.

4 É preciso destacar que no sul da colônia o processo de mestiçagem entre o português e o índio forjou também o caboclo paulista, agente fundamental na apropriação portuguesa do território e suas riquezas. Ver Ribeiro (2006).

5 "No curto espaço de quatro anos, na década de 1750 , foram criadas na Amazônia brasileira cerca de sessenta povoações. Um verdadeiro boom urbanizador... Aldeamentos indígenas foram radicalmente transformados, convertendo-se em vilas planejadas no campo da racionalidade geométrica." (RISÉRIO, 2012, p. 127-128). intermediário entre os agentes inovadores, portadores dos impulsos que modificam/ perpetuam sua distinção em sistemas, e as realidades locais e regionais diversas.

Naformulação deSantos, aos dois sistemas defluxos correspondem relações do mercado de trabalho. Resultando de interaçôes de impulsos de modernização que se difundem a partir dos centros do sistema - tecnologias aplicadas à produção e sua organização, padróes de consumo e contextos culturais a eles relacionados, entre outros aspectos -, os circuitos refletem relaçóes peculiares entre trabalho e capital. Em regra, as rodadas de tecnologia foram poupadoras de mão de obra. Tornaram supérfluos contingentes de trabalho não especializado e simultaneamente elevaram as exigências de especialização para os segmentos de máo de obra ainda requisitados. Ao mesmo tempo, essas rodadas adentram o sistema econômico introduzindo novos produtos, ou novos conjuntos articulados de produtos, na cadeia de consumo, em geral no topo dessa cadeia. O sistema avança renovando as contradições entre os circuitos, mas dificilmente diluindo-as.

Importa discutir o quanto o ambiente Amazônia insere algo novo nesse quadro e o quanto ele se modifica no contexto brasileiro contemporâneo, com o crescimento econômico dos anos 2000. Obviamente não pretendemos oferecer respostas definitivas a essas questôes, restando trazê-las ao debate e tentar uma contribuição.

A criação de reservas de mão de obra foi uma questão crucial na formação do espaço econômico brasileiro. Num território vasto e desconhecido, o conhecimento do colonizador não se comparava ao saber concreto do nativo. A criação de mercadorias trilhou o caminho do trabalho escravo do homem trazido da África. A força de trabalho indígena tornou-se de início impossível ou segunda opção a contragosto. Mas na Amazônia a agricultura em larga escala não conseguiu instalar-se em função das características do ambiente. Ela veio a se metamorfosear numa economia extrativista peculiar, o extrativismo de coleta. ${ }^{3}$ Ali, num ecossistema de características únicas, sobre o qual o nativo era o único detentor de conhecimento, este se transformava em trabalho (altamente) qualificado. Ao contrário do restante da colônia, ocorre algo muito distinto do índio ou mestiço como mão de obra de segunda categoria. ${ }^{4}$ A população cabocla amazônica, à semelhança do mestiço no restante do Brasil, irá formar parcela da sociedade privada de direitos. Mas desde o primeiro momento se estabelece uma relaçáo especial com o mercado de trabalho. $\mathrm{O}$ quadro natural oferece ao não proprietário formas de negar (pelo menos relativamente) a submissão às formas de trabalho de interesse exclusivo do colonizador, e mais tarde a empresa capitalista (COSTA, 2012a). Para isso, contribui a abundância de recursos para a sobrevivência (valores de uso) e gêneros passíveis de valorização no mercado, assim como aquele herdado que, embora constantemente classificado como arcaico, mostrase repetidamente rico e dotado de eficiência reprodutiva específica para assegurar os meios de vida de parcelas extensas da população.

Esse processo se consolida ainda nos Seiscentos, ganha instituiçóes e permanência com a ação jesuítica e prolonga-se, modificado, com as reformas introduzidas pelo Diretório dos Índios, promulgado pelo marquês de Pombal em 1755. Este visava a retirar a população indígena da influência direta dos jesuítas. Tal modificação seria levada a cabo pela transformação dos aldeamentos indígenas em vilas, cujo espaço e práticas seriam regulados nos termos de uma prática "urbana":5 a transformação das aldeias jesuíticas em vilas, enraizando na Amazônia a apropriação do espaço e suas formas de riqueza, incluídos aí o saber e a força de trabalho índia-cabocla imprescindível no acesso às drogas do sertão (RISÉRIO, 2012). 
O período da borracha na Amazônia renova o valor do conhecimento tradicional sobre o ecossistema. O caboclo foi o fator trabalho fundamental na busca do látex, agora sob o sistema de controle da mão de obra do aviamento. Esgotados os altos e baixos da produção da borracha, a população se adapta a outras formas de produção e reproduçáo da vida, particularmente a pequena produçáo agropecuária. Esses altos e baixos incluem o fracasso da maior empresa do capitalismo mundial, a Ford, que permanece por 18 anos na regiáo e fracassa. Mais do que perda de interesse ou realocação racional de investimentos, a companhia não obteve êxito na longa e dispendiosa luta com as condiçôes locais, em parte devido a sua relação conflituosa com a mão de obra local (COSTA, 2012c, p. 35), a população cabocla, em parte em funçáo da singularidade amazônica, a qual tanto é natural como social:

É natural na medida em que deriva de ecossistema único no planeta, onde os processos reprodutivos dos ciclos vitais da natureza supóem condiçôes não familiares a estruturas produtivas do capitalismo enquanto sistema... É também singular enquanto espaço socioeconômico com características de fronteira onde os trabalhadores diretos podem ter acesso a recursos da natureza, seja pela abundância relativa de terras, seja pela impossibilidade técnica ou política de estabelecimento do monopólio da propriedade do solo por uma classe social especifica, seja por uma conformação do Estado que o impede de garantir um tal monopólio, ou ainda pela combinação variada desses elementos. Tais características, bloqueando a formação de um mercado de trabalho, trazem complicaçóes que requerem soluções emergenciais para o empreendimento capitalista...

A singularidade do espaço amazônico permanece como um aspecto marcante na realidade contemporânea amazônica, após as notáveis modificaçóes pelas quais passa a região nas últimas quatro décadas? Não há resposta definitiva, mas um olhar sobre o mercado de trabalho e as relaçóes econômicas correntes ajuda a jogar luz sobre a questão.

Os últimos quarenta anos foram de intensa transformação. A urbanização revela-se no acelerado crescimento do número de centros urbanos e da população ali assentada, com consequências sobre a modificação do bioma cuja expressão mais comumente mencionada é a agressão à floresta. Difundem-se as condições de infraestrutura de transportes e comunicaçóes, intensificando uma rede de condiçôes urbanas, técnicas e produtivas que alcança a região de forma abrangente. De forma mais sutil, ocorre a difusão de formas de consumo e capilarização de instituiçôes antes restritas à cidade, das relaçôes de trabalho e previdência, da organização da sociedade civil, do exercício da cidadania que se instala nos espaços de vida e produção dispersos na floresta e na cidade (BECKER, 2004). São as condiçóes de urbanização extensiva (MONTE-MÓR, 1994), a dispersão e significação daquilo que uma vez nasceu como traço físico ou prática social na cidade, mas que alcança virtualmente todo o espaço social na sociedade urbana.

$\mathrm{O}$ recente crescimento da economia brasileira, que se estende à Amazônia, também introduz mudanças no cenário regional. Algumas regióes têm experimentado expansão econômica e demográfica elevada, particularmente onde se instalou recentemente a indústria extrativa mineral, como o caso do sudeste do Pará. Áreas urbanas se expandiram de modo célere no último decênio, abrigando população que se desloca em busca de oportunidades criadas direta e indiretamente pela atividade mineradora, sua cadeia e pela base urbana que lhe é indispensável. 
Ao mesmo tempo, mesmo em face da expansão de condiçóes de emprego formal, permanecem elevados os percentuais de informalidade. Conserva-se alta a parcela da população que recorre a estratégias de reprodução que não passam pelas relaçóes de trabalho formais. É possível dizer, no entanto, que o significado da "informalidade" não se esgota na negatividade implícita na abordagem usual da questão, mais ainda no contexto da Amazônia contemporânea. Ali, formas alternativas de organizaçáo do trabalho e da produção possuem tanto uma longa tradição e enraizamento na prática social quanto um substrato real dado pelas condições naturais abundantes. Essa abundância possui (ou pode ser transformada em) extenso conjunto de valores de uso de absoluta originalidade, capazes de assumir valor de troca realizável no mercado. Esse processo ademais se abre à atuaçáo de pequenos agentes (em termos de posse de recursos) e às formas cooperativas e solidárias de produçáo.

Como sugere a abordagem de Costa (2012b), a existência de alternativas de sobrevivência do trabalhador na Amazônia teve como fundamento, desde os primeiros momentos, a existência de recursos naturais e de um saber prático detido pelo homem da região. Esse cenário, nos parece, oferece mais do que opçóes de trabalho e renda, na medida em que tem como base um bioma de riqueza extensa e ainda pouco conhecido por meios formais, amplamente sujeito e favorável à introdução de novas formas de valor, de "trabalho novo" (JACOBS, 1970), o que, como argumentado por diversos autores, é aspecto fundamental para o avanço econômico (FURTADO, 2009; BECKER, 2009). Retornando à proposição de Milton Santos sobre as características dos dois circuitos da economia urbana, é importante rememorar que o autor destaca o circuito inferior por seu caráter criativo intrínseco, embora impulsionado não raro pela carência; ainda assim, para além do negativo implícito, o reino do informal é também o do experimental, do novo, do que se abre para a experiência cotidiana e por isso para um panorama de desenvolvimento alternativo.

Nossa intenção aqui, pouco mais além de colocar a questão, é discutir aspectos da realidade no sudeste do estado do Pará, a fim de permitir uma aproximação empírica para as questôes sobre a permanência e a importância das distinçôes entre o trabalho formal e informal na Amazônia.

\section{EVIDÊNCIAS PARA O SUDESTE PARAENSE}

Nesta seção, são apresentados dados secundários e informaçóes coletadas durante pesquisa de campo realizada em julho de 2012 no sudeste paraense. O conjunto de municípios selecionados compreende a região da Terra do Meio/ Carajás: Canaã dos Carajás, Marabá, Ourilândia do Norte, Parauapebas, Tucumá, São Félix do Xingu e Xinguara. 
Figura 1: Municípios selecionados - Pará

\section{Municípios do Pará e municípios da área Urbis-1}

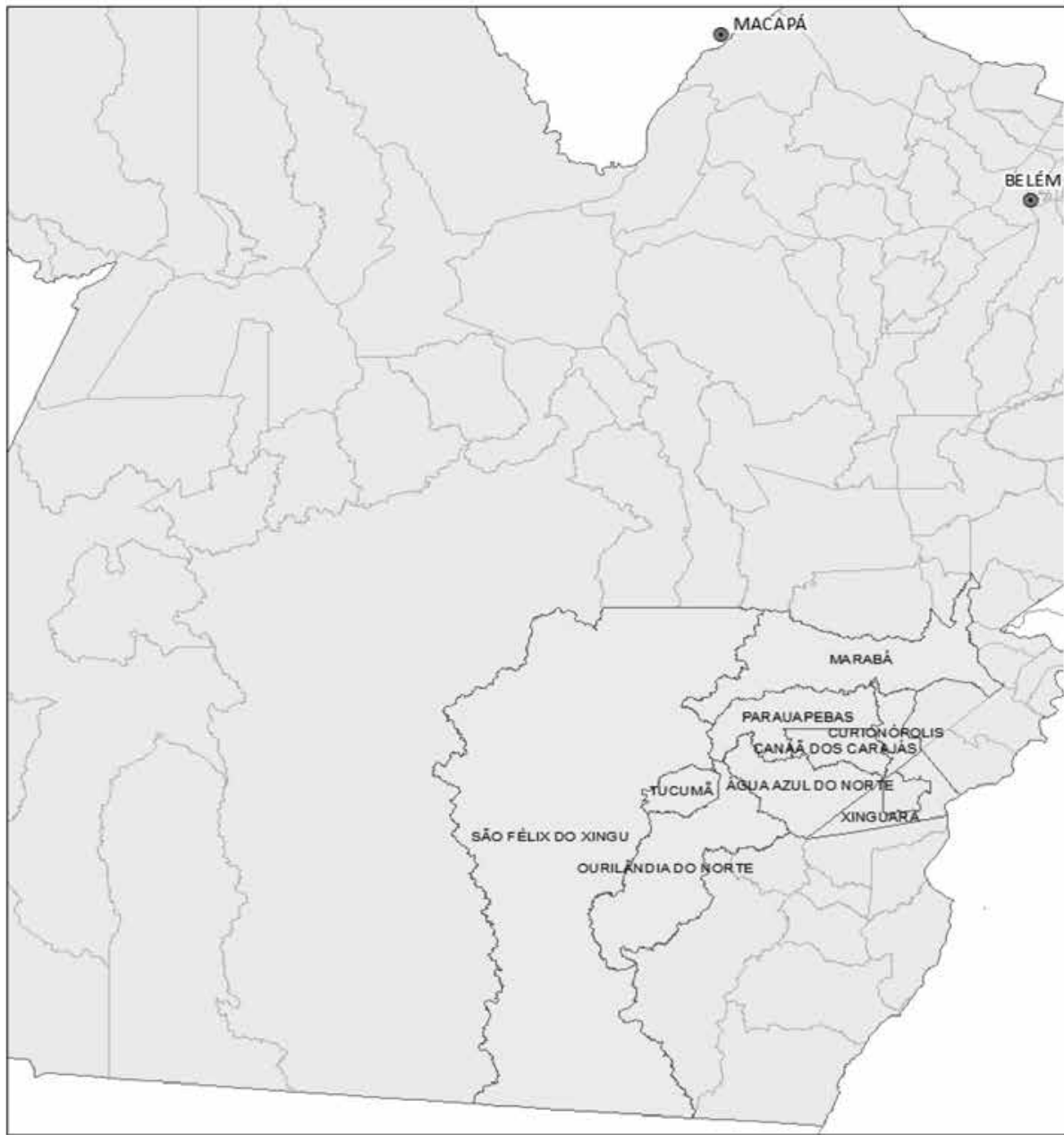

Legenda

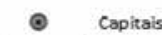

mun_urbis selection

Demais municipios do Par
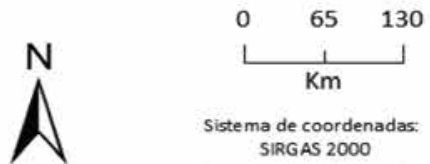

Sistema de coordenada: SIRGAS 2000

Fonte: Craice e Souza (2013).

A escolha do estado do Pará se justifica por ser, dentre os estados da Amazônia Legal, o que apresenta o mosaico mais diverso de novas formas socioespaciais e de seus arranjos espaciais, configurando-se um recorte representativo da produção da urbanização extensiva na Amazônia.

Encontramos no Pará assentamentos, projetos de colonização, populaçóes tradicionais, ribeirinhos, floresta, acampamentos de sem-terra e conflitos, cidades médias e uma importante capital, a mineraçấo das grandes companhias mineradoras e dos núcleos de garimpo, enfim, um mosaico dos atores e de suas estratégias para sua integração às estruturas econômicas regionais, nacionais e internacionais. (INPE, 2011, p. 19). 
A missão de campo assumiu como pontos extremos as cidades existentes antes da implantação dos grandes projetos federais na região. Marabá e São Félix do Xingu foram fundadas no período da extração da borracha, vivenciando o escoamento dessa produção pelos rios Tocantins e Xingu, respectivamente. Além da acessibilidade e da possibilidade de exploração extrativista (borracha, castanha, jaborandi), tais cidades tinham em comum a riqueza mineral, explorada a princípio por garimpeiros e depois por empresas mineradoras, a partir dos anos 1960. As açóes do Governo Federal passaram também por assentamentos rurais e rodovias, alterando completamente a dinâmica do território.

Parauapebas surgiu como apoio à atividade de mineraçáo. O apoio do GETAT aos assentamentos rurais e à produção agrícola deu origem ao núcleo inicial de Canaã dos Carajás. Já uma parceria entre Governo Federal e a empresa Andrade Gutierrez envolveu a criação dos núcleos iniciais de Tucumã e Ourilândia. A dinâmica (mais recente) da pecuária na região é vista com maior clareza no município de Xinguara (INPE, 2012).

A regiáo é marcada por um histórico de conflitos pela posse da terra, com práticas sociais e ambientais abusivas. O grande montante de recursos movimentado pelo circuito superior (pecuária, comércio e serviço de alto padrão, mineraçáo) torna a migração um processo importante (CRAICE; SOUZA, 2013).

\section{DinÂMICA DO CIRCUITO SUPERIOR}

A regiáo em foco é marcada por uma dinâmica acelerada nos anos recentes. A mineração e a agropecuária em pequena e larga escala movimentam os investimentos de maior monta e orientam/induzem investimentos no comércio e nos serviços, provocando ainda grandes movimentos migratórios de estados mais empobrecidos do Norte e Nordeste.

Esse conjunto de municípios tem expandido seu peso na economia do estado do Pará. No ano de 1996 essa participação era de 8,6\% do PIB estadual; em 2009, a região alcança algo próximo a $20 \%$, um quinto do produto total do estado. Tal escalada está principalmente ligada ao desempenho da indústria (extrativa mineral) localizada nos municípios de Parauapebas e Canãa dos Carajás. Comparando o crescimento médio dos municípios em foco e o do restante do estado, temos $10 \%$ de incremento médio anual para o primeiro conjunto contra $4 \%$ para o restante do Pará. Chama atenção, no entanto, o comportamento instável e cíclico desse ritmo de crescimento, e sua aderência a ciclos econômicos internacionais, como atestam os vales que coincidem com as crises internacionais de 2003 e 2008, fato óbvio em função da natureza exportadora da principal atividade industrial da região: a mineração de ferro.

Em termos da distribuição dessa produção entre os municípios, Parauapebas e Marabá dividem as contribuiçôes mais expressivas. Em 2009, Parauapebas representava $52 \%$ do PIB do conjunto dos municípios em análise, enquanto Marabá detinha 28\%, tendo sido este o cenário médio ao longo dos dez anos que viemos analisando. Canãa dos Carajás teve um crescimento importante no período, visto que representava apenas $1 \%$ da produção do conjunto contra $8 \%$ dez anos mais tarde.

Em relação à distribuição setorial do emprego, destacam-se a perda de peso da agropecuária, o crescimento do comércio e da construçáo civil e uma queda da participação relativa dos empregos diretos na mineração. O grupo comércio e serviços, no entanto, teve acréscimo importante, principalmente no comércio. É possível que esse crescimento se conecte indiretamente à base exportadora minerária, que nesse caso 
transmitiria dinamismo a outros setores, seja por demandas intersetoriais, seja pela renda gerada na forma de salários e outras remunerações que chegam assim ao terciário local.

Gráfico 1: Pará - Municípios selecionados: Evolução da distribuição setorial (relativa) do emprego, 1990-2010.

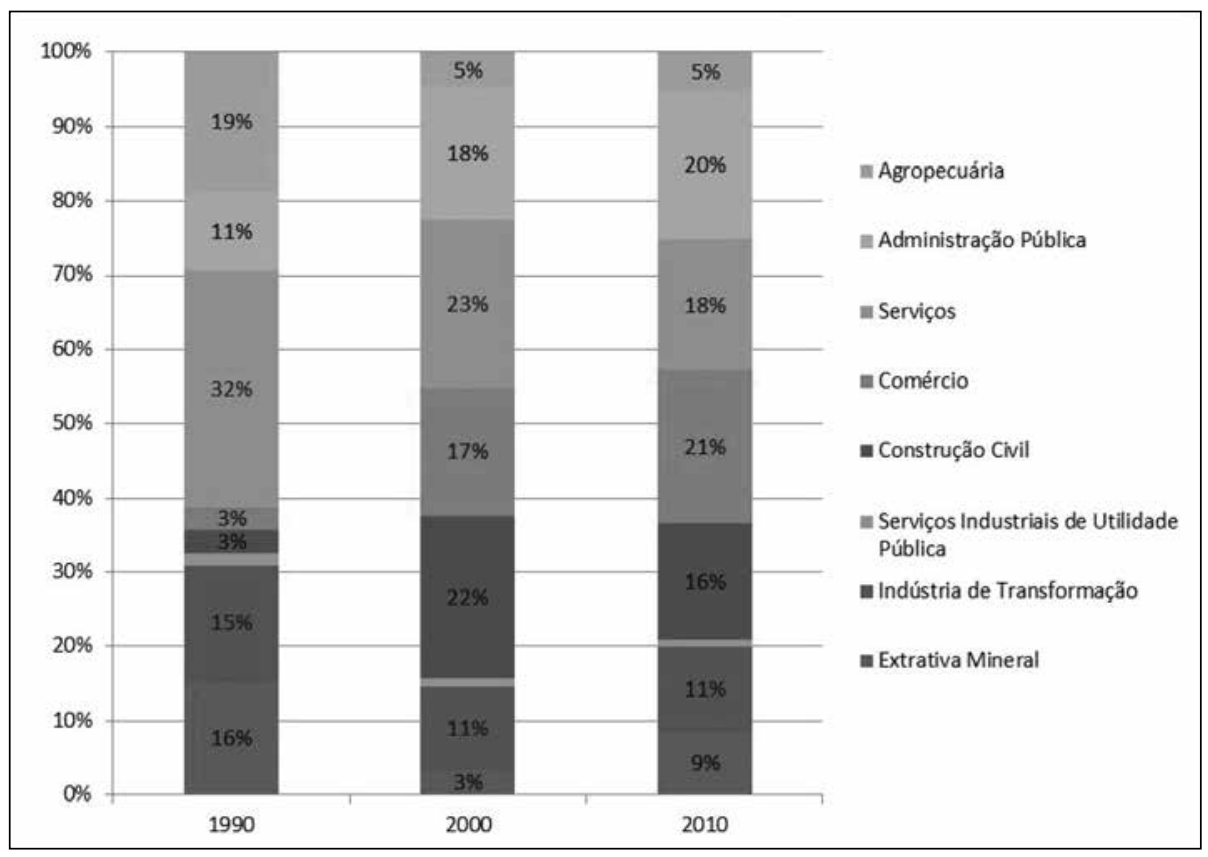

Fonte: RAIS-MTE.

Se analisarmos a composição do emprego por município, teremos duas tendências mais facilmente identificáveis. De um lado, Marabá e Parauapebas, com tendência de crescimento do emprego formal nos setores de comércio e serviços e construção civil, além das indústrias extrativa mineral e de transformação. Marabá, centro regional de importância há décadas, aparentemente passa a compartilhar com Parauapebas a condição de polo de serviços. No outro extremo, temos Xinguara, São Félix do Xingu e Sapucaia, com importância ainda elevada da agropecuária e da administração pública. O grupo intermediário, formado por Ourilândia, Tucumã e Canãa dos Carajás, possui mercados de emprego formal ainda pequenos, mas em processo de diversificação.

\section{Circuito INFERIOR E ECONOMIA DOS SETORES POPUlARES}

Na regiáo visitada, a produçáo ligada à economia dos setores populares configurase principalmente pelas seguintes atividades:

- produção familiar em torno da agricultura (sobretudo arroz, feijão, milho, mandioca, hortaliças, cacau), pecuária (sobretudo leiteira), pesca e piscicultura;

- comércio em pequena escala, sobretudo do setor de confecçóes e pequenos negócios nos bairros distantes do centro: pequenas "vendinhas", salóes de beleza, bares e restaurantes;

- ambulantes do setor de alimentação, confecções, produtos eletrônicos, CDs e DVDs "piratas" e importados diversos. 
Os dados do Censo Demográfico 2010 apontam um grau de informalidade nos municípios visitados superior ao brasileiro. A soma dos empregados sem carteira, por conta própria e não remunerados para o conjunto dos oito municípios é cerca de 54\%, valor maior do que a média nacional (47,7\%) (Gráfico 2). Ao se observar os municípios separadamente, a soma dos empregados sem carteira, por conta própria, não remunerados e na produção para o próprio consumo chega a 73,3\% em São Félix do Xingu e 71,3\% em Tucumã (contra $47,7 \%$ no Brasil e $67,2 \%$ em todo o Pará). Os trabalhadores por conta própria também representam um percentual superior ao brasileiro, embora inferior à participaçâo no estado do Pará. Os não remunerados e os que produzem para o próprio consumo são muito mais representativos que no caso brasileiro, sendo que em Sáo Félix do Xingu 12,5\% dos ocupados se encaixam neste último grupo (Gráfico 3).

Gráfico 2: Pará - Municípios visitados - Total: Percentual da posição na ocupação no trabalho principal (ocupados com 10 anos ou mais de idade), 2010.

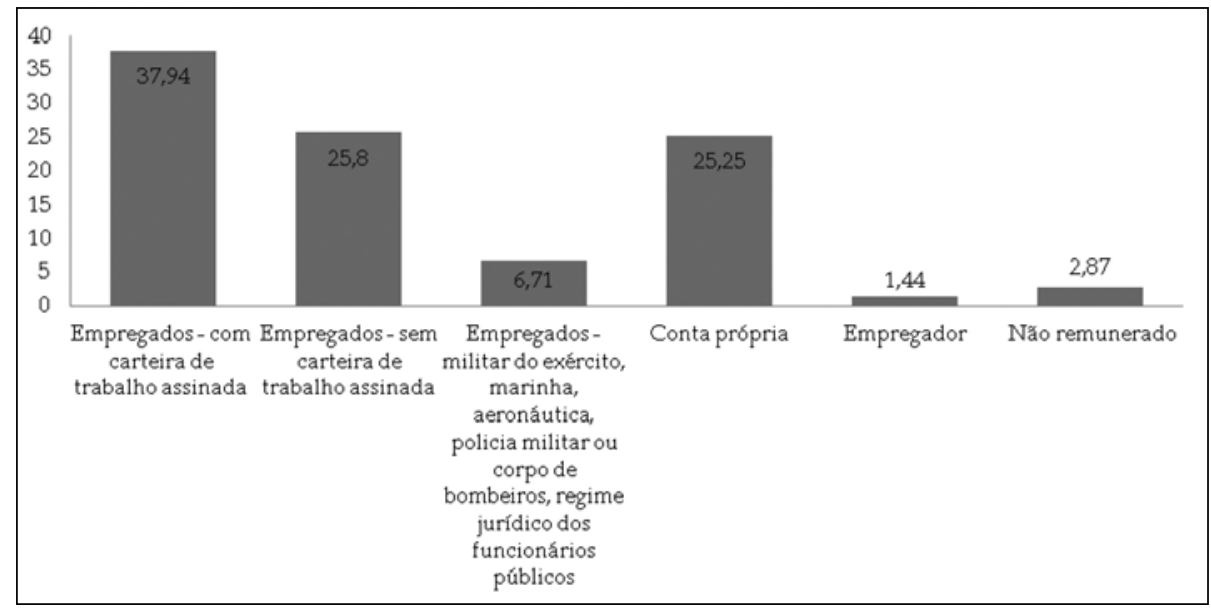

Fonte: Censo Demográfico 2010 - IBGE.

Gráfico 3: Pará - Municípios visitados: Posição na ocupação no trabalho principal (ocupados com 10 anos ou mais de idade), 2010.

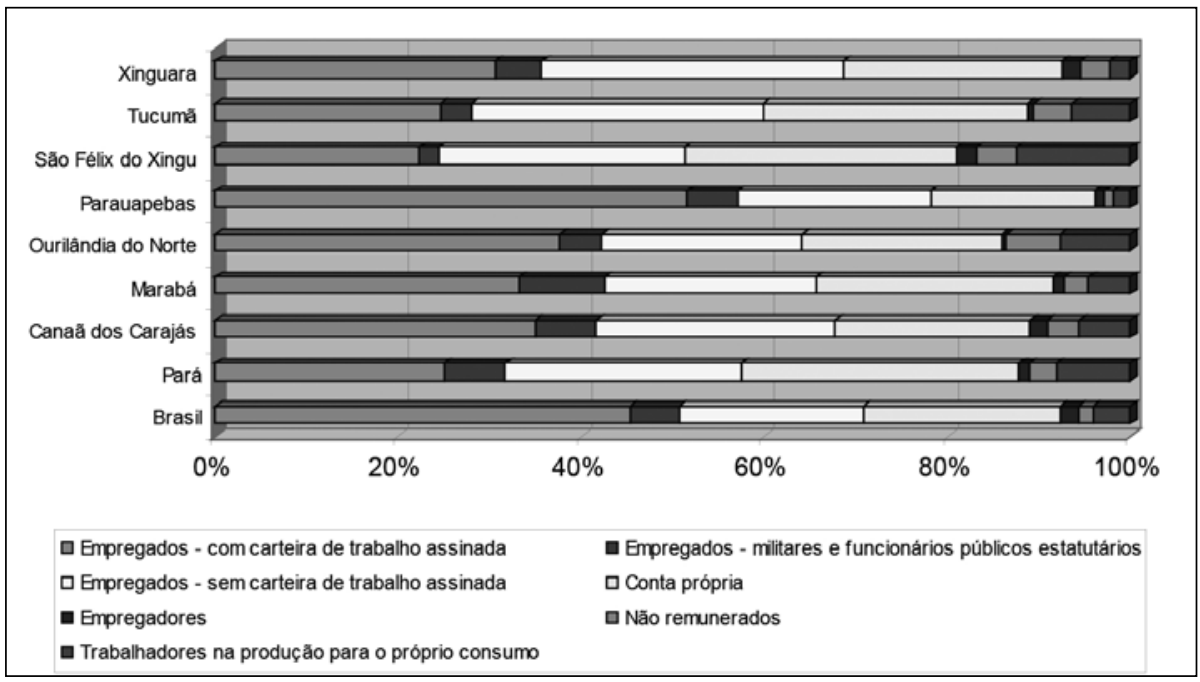

Fonte: Censo Demográfico 2010 - IBGE. 
O gráfico a seguir apresenta o elevado papel da agropecuária e pesca na absorção de trabalhadores (destaques para São Félix do Xingu e Tucumã), além dos serviços, comércios e mercados (destaques para Marabá, Parauapebas e Xinguara) e das ocupaçóes elementares, que incluem os ambulantes, domésticos, entre outros (destaques para São Félix e Tucumã).

Gráfico 4: Pará - Municípios visitados: Grandes grupos de ocupação no trabalho principal (ocupados com 10 anos ou mais de idade), 2010.

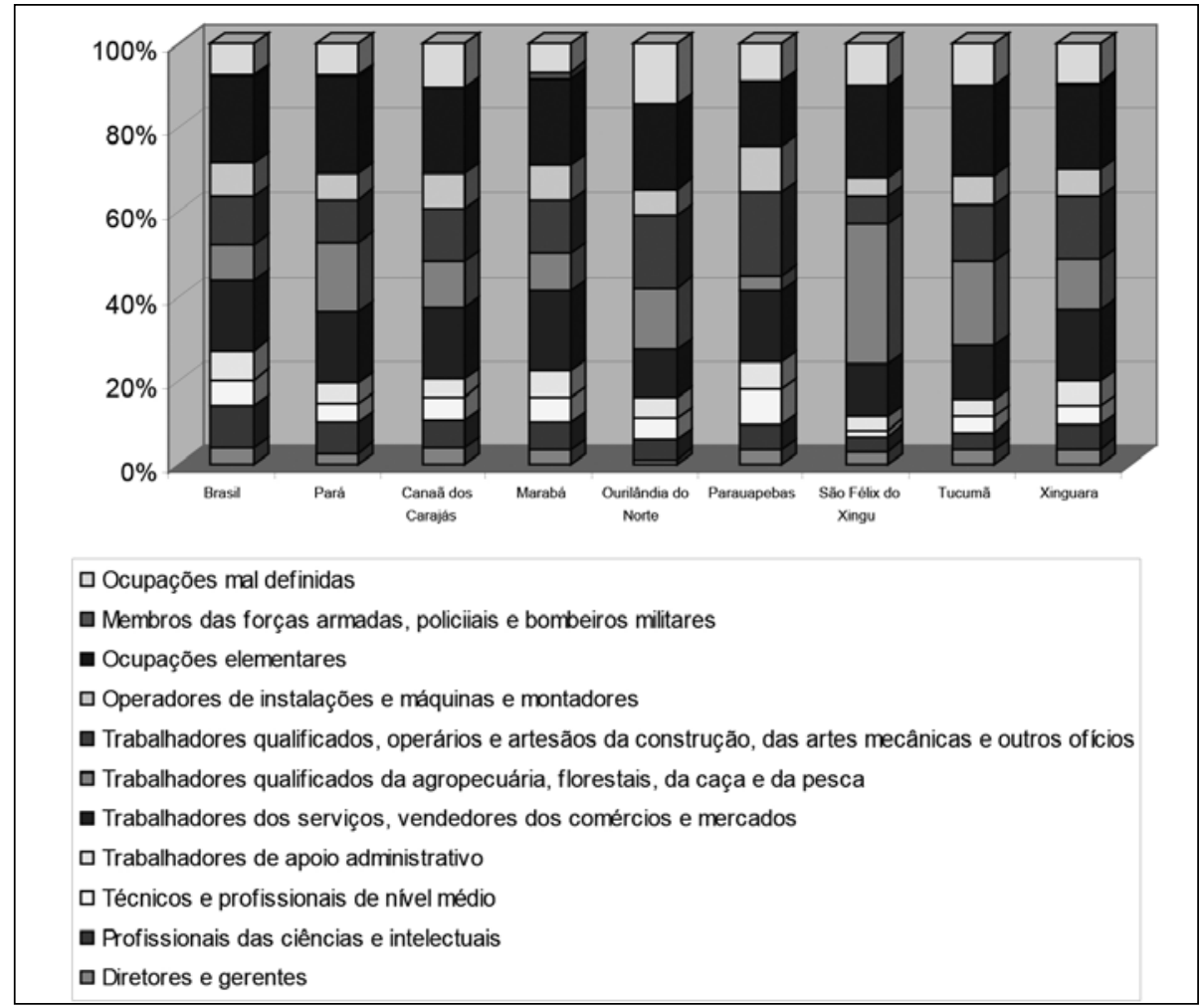

Fonte: Censo Demográfico 2010 - IBGE.

A agricultura familiar, na maior parte dos casos, caracteriza-se pela produção para o próprio consumo com venda do excedente. Os principais pontos de comercialização, tanto da agricultura quanto da pecuária e da pesca familiares, são as feiras municipais. Os produtos ofertados vão das carnes (boi, frango vivo, camarão e peixes) às diversas variedades de farinha de mandioca e grãos, passando também pelas verduras e frutas. A produção de alimentos e a criação de animais, no entanto, é incapaz de abastecer o mercado local, sobretudo devido ao ritmo de transformação da região. A falta de apoio técnico e de infraestrutura para o transporte da produção é também apontada como causa. Essa é a posição, por exemplo, dos técnicos da FECAT (Federação das Cooperativas de Agricultura Familiar do Sul do Pará). A FECAT, entidade de 'apoio logístico, operacional, técnico e político' à agricultura familiar, possui uma de suas bases em Marabá e atua prioritariamente em projetos de assentamento, oferecendo orientação com relação à fruticultura e à diversificação produtiva.

Em Tucumã, Ourilândia e São Félix do Xingu a produção de cacau é significativa. A Coopertuc - Cooperativa Agrícola Mista de Tucumã, fundada 
pela Andrade Gutierrez em 1982 - possui papel importante na articulação entre o pequeno produtor local e as grandes empresas compradoras do cacau (Cargill, Nestlé, Barry Callebaut e outras). Esse papel é desempenhado também pela Cappru - Cooperativa Alternativa de Pequenos Produtores Rurais e Urbanos, em São Félix do Xingu, criada em 1992 a partir de quatro associaçóes de produtores locais. Realiza, além da intermediaçáo do cacau, açóes de acompanhamento e capacitação dos produtores, por meio de recursos captados juntos aos governos estadual e federal. Outras iniciativas são um projeto piloto para certificação do cacau orgânico, a manutenção de um banco de sementes nativas e o apoio ao artesanato (licor de cacau e embalagens a partir das folhas secas do cacau).

O setor de comércio e serviços em pequena escala é significativo em toda a regiáo e parece acompanhar o ritmo dos investimentos de grande monta destinados ao circuito superior. Segundo o presidente do Sindicato dos Comerciários de Marabá, João Luiz, as expectativas de investimento na mineração alavancam o setor (principalmente os serviços mecânicos e elétricos, mas também os serviços pessoais e o comércio). Do mesmo modo, expectativas de paralisaçáo de investimentos geram demissóes e enfraquecimento do setor.

O comércio de bairro é acessado, na maior parte dos casos, em situaçóes emergenciais. Nesses casos, a compra é feita em unidades fracionadas, o que não é possível nos grandes supermercados. Praticamente tudo que é vendido não é produzido localmente, à exceção de poucos produtos da agricultura familiar. Quanto aos serviços pessoais, boa parte dos entrevistados afirmou que estes são de baixa qualidade e que falta qualificação e apoio para seu aprimoramento.

Em Marabá e Sáo Félix do Xingu, o turismo ligado aos rios (praias) gera renda para ambulantes do setor de alimentação e barcotáxis. O turismo de pesca também é considerável, especialmente em São Félix, como apontado por funcionárias da Colônia dos Pescadores Z65 de São Félix do Xingu. A Colônia agrega cerca de 400 famílias que vivem principalmente da pesca. No entanto, a renda da atividade náo é suficiente, dados os altos custos enfrentados (com material, transporte etc.), dificuldades no acesso ao crédito, entre outros. Por essas dificuldades, a Colônia possui demandas definidas (e não atendidas), como o apoio técnico por meio de estudos (sobre o período adequado da piracema para as espécies locais, berçário de espécies, tanques-rede, entre outros), o apoio à pesagem dos peixes no momento da chegada dos pescadores e o apoio ao turismo de pesca de base comunitária (integraçáo entre o turista e o pescador local).

O artesanato é bastante incipiente e pulverizado nos municípios pesquisados. Destaca-se a Cooperativa de Bioarte de Tucumá, criada a partir de curso de capacitação em artesanato oferecido pela Estação do Conhecimento Vale desse município. A Cooperativa produz brincos e colares (biojoias) a partir de sementes nativas e conta hoje com 34 mulheres. A Estação do Conhecimento realizou a capacitação das primeiras cooperadas, a compra do maquinário e das primeiras matérias-primas, além de ceder o espaço para trabalho e exposição dos produtos. 


\section{INICIATIVAS DE APOIO}

Do ponto de vista do apoio, o CredCidadáo, programa de microcrédito do governo do estado do Pará, possui escritórios nas prefeituras de Marabá e Xinguara. Nesse município, o programa atende sobretudo os revendedores do setor de confecção, embora também tenha atendido aos produtores da agricultura e mototaxistas. Entretanto, apresenta ainda baixo alcance, dada a dificuldade de atendimento dos requisitos por parte dos solicitantes (documentação das terras, nome no SPC ou SERASA etc.).

Todas as prefeituras visitadas oferecem cursos de qualificação profissional de curta duração na área de serviços pessoais, informática, eletricista, entre outros. Apenas em Xinguara encontramos açôes de apoio voltadas especialmente à Economia Solidária. A Prefeitura Municipal conta com um Departamento de Economia Solidária ligado à Secretaria de Desenvolvimento Econômico, com uma legislação específica para a economia solidária (aprovada em julho de 2006) e com um fundo municipal de apoio à economia solidária (FundoSol). Tais iniciativas tiveram origem na açáo dos membros da Cooperativa de Serviço e Apoio ao Desenvolvimento Humano e Sustentável Atioro - Coopatioro, fundada em 1997 com apoio da Diocese e da Comissão Pastoral da Terra (CPT), e que hoje se denomina uma Associação (Apatioro) com o objetivo do fomento à pequena produçáo popular e solidária. São açôes do Departamento de Economia Solidária no município: cadastramento dos ambulantes; apoio às feiras locais; manutenção de um posto de apoio ao empreendedor no Mercado Municipal; cessão de uma loja na rodoviária para exposição dos produtos dos artesãos locais; tentativas de organização dos produtores para a compra coletiva de insumos; orientaçôes para a estruturação de pequenos empreendimentos, participação em licitaçôes, formalização das atividades e uso do microcrédito produtivo.

Quanto ao apoio universitário, a Incubadora Tecnológica de Empreendimentos Solidários do Sul e Sudeste Paraense (ITESP/UFPA), localizada em Marabá, propóese a assessorar grupos já existentes com o fim de aprimorar a produçáo e potencializar sua atuação na região (Marabá e entorno). O público-alvo é composto de agricultores familiares, agricultores urbanos e periurbanos, grupos de mulheres em condiçóes de vulnerabilidade, grupo de artesãos, associações de moradores, entre outros.

Uma característica das açôes de apoio é a ausência de integração entre as mesmas: os programas das prefeituras não contemplam parcerias com ONGs, SEBRAE ou Universidades - quando contemplam, as açôes conjuntas são incipientes. É o caso da Agência de Desenvolvimento Econômico e Social de Canaã dos Carajás - Agência Canaã, entidade sem fins lucrativos que conta com representantes da iniciativa privada, do terceiro setor, do poder público e da sociedade civil organizada. A entidade, sem fins lucrativos, é mantida com recursos da Prefeitura e da Vale, e tem como um de seus objetivos a geração de trabalho e renda no município, tendo apoiado projetos de piscicultura, apicultura e hortas comunitárias. Entretanto, as açôes são ainda embrionárias, uma vez que a Prefeitura Municipal não atua de forma significativa e o apoio técnico é fraco.

Entre os grupos apoiados pela Agência Canaã encontra-se a Associação de Artesãos e Artesãs Solidários de Canaã dos Carajás, grupo de mulheres ligadas ao movimento nacional da Economia Solidária. Desde 2005, o grupo atua junto à Prefeitura e a outras instituiçóes buscando compradores e parceiros para divulgaçáo 
6 Ver, por exemplo, Costa (2005, 2006, 2009), Homma (2005, 2006), CGEE (2009, 2011). e comercialização dos produtos e também na área de capacitação. A metodologia utilizada passa pela valorização e divulgação dos princípios da Economia Solidária em todas as açôes, participação nos Conselhos Municipais e parcerias com as escolas e demais instituiçóes de formaçáo. $\mathrm{O}$ grupo conquistou uma loja na avenida central do município, cedida pela Prefeitura, e mais dois espaços, sendo um na sede e o outro distante. Atualmente, são 28 grupos, embora 84 famílias já tenham passado pela Associação. Alguns dos grupos apoiados já celebraram contratos de venda para a Prefeitura Municipal (uniformes) e a Vale (uniformes e lanches).

\section{CONSIDERAÇÕES FINAIS}

Esta investigação busca colaborar para a discussão sobre o desenvolvimento atual e futuro da região Amazônica, podendo subsidiar açôes de fortalecimento e expansão da economia dos setores populares, entendendo ser esta uma alternativa para a geração de emprego e renda baseada em atividades de baixo impacto ambiental e intensivas em trabalho. Embora essa alternativa seja ressaltada por boa parte dos trabalhos acadêmicos sobre a região, ${ }^{6}$ observam-se poucos desdobramentos em termos de políticas públicas e açóes de outros agentes na região.

A produçáo em pequena escala que caracteriza o circuito inferior na regiáo estudada padece das mesmas dificuldades e gargalos verificados em outras regiôes do país: baixa qualificação em geral, dificuldades para captação de crédito, ausência de apoio técnico e de articulação com escolas técnicas e universidades. Outro aspecto importante é que essa produção apresenta poucos vínculos no nível local e regional, quase sempre dependendo de insumos vindos de fora do estado, o que encarece os produtos e impede a formação de cadeias produtivas locais. Ademais, alguns setores de grande potencial, como o turístico, de fitoterápicos, reciclagem e extrativismo florestal de produtos não madeireiros são praticamente inexistentes. Em boa parte dos casos, demandas específicas de apoio técnico são claramente definidas pelos próprios trabalhadores e grupos entrevistados. Conclui-se que o apoio a essas iniciativas possui grandes efeitos potenciais, em termos de geração de trabalho e renda, sobretudo para a população não inserida nos grandes investimentos minerários previstos e em implantação na regiáo.

A articulação entre o circuito superior e o inferior é ainda muito fraca, ou praticamente inexistente; entretanto, o crescimento recente do circuito superior abre possibilidades para um fortalecimento do circuito inferior, tendo como exemplos maiores a demanda por alimentos e por serviços produtivos e pessoais. Observa-se também que esse potencial de articulação não se realiza por falta de apoio institucional e de mediação entre os dois setores. Existe grande espaço para inovação e coordenação de ações entre os dois setores, implicando o envolvimento dos diversos atores e rompendo com a relativa acomodação na linha de ação de grandes produtores, que utilizam grandes fornecedores distantes; faltam também referências e/ou repertório para os atores nos dois circuitos e nas possíveis mediaçôes, para promover as sinergias necessárias.

A desarticulação ou a simples vacância de elos inteiros das cadeias produtivas contrastam com o crescimento do sistema econômico regional. Essa realidade 
configura ao mesmo tempo um empecilho e uma oportunidade econômica de monta. Naqueles setores mais amigáveis à atuação de agentes pequenos, o crescimento de açôes de natureza cooperativa, que contribuam para superar o baixo nível de organização e capacidade de ação em ambiente de mercado capitalista, pode ser mais facilmente desenvolvido.

Surge como caminho possível a articulação visando a mudanças institucionais que orientem o "trabalho novo", a partir do conhecimento tradicional e dos saberes locais. Um novo paradigma de exploração dos recursos da floresta que permita a incorporação das diversas fatias da população, permitindo elos mais intensos nas cadeias produtivas e a exploração sustentável do ecossistema, como proposto por Becker (2009). O desafio maior parece estar na integração institucional necessária entre setor público, instituiçôes produtoras de conhecimento, o setor privado, e as diversas unidades produtivas da economia popular, familiar e solidária.

\section{REFERÊNCIAS BIBLIOGRÁFICAS}

BECKER, B. K. Amazônia: geopolítica na virada do III milênio. Rio de Janeiro: Ed. Garamond, 2004.

BECKER, B. K. Articulando o complexo urbano e o complexo verde na Amazônia. In: Um projeto para a Amazônia no século 21: desafios e contribuiçôes. Brasília: CGEE, 2009.

BECKER, B. K. Dinâmica Urbana na Amazônia. In: Diniz, C. C.; Lemos, M. B. (Org.). Economia e Território. Belo Horizonte: CEDEPLAR, 2005.

CENTRO DE GESTÃO E ESTUDOS ESTRATÉGICOS (CGEE). Soerguimento tecnológico e econômico do extrativismo na Amazônia. Brasília: CGEE, 2011.

CENTRO DE GESTÃO E ESTUDOS ESTRATÉGICOS (CGEE). Um projeto para a Amazônia no século 21: desafios e contribuições. Brasília: CGEE, 2009.

COSTA, F. de A. Arranjos e Sistemas Produtivos e Inovativos Locais - As Possibilidades do Conceito na Constituição de um Sistema de Planejamento para a Amazônia. Revista Brasileira de Inovação, 5(1), jan./jun. 2006.

COSTA, F. de A. Formação Agropecuária da Amazônia: os desafios do desenvolvimento sustentável. Belém: NAEA, 2012a.

COSTA, F. de A. Formação rural extravista na Amazônia: os desafios do desenvolvimento capitalista (1720 - 1970). Belém: NAEA, 2012b. (Coleção Economia Política da Amazônia).

COSTA, F. de A. Grande Capital e Agricultura na Amazônia: O projeto Ford no Tapajós. Belém: NAEA, 2012c. (Coleção Economia Política da Amazônia).

COSTA, F. de A. Questão Agrária e Macropolíticas na Amazônia: novos momentos, grandes desafios. Revista do Centro de Estudos Avançados, 53, jan./mar. 2005.

COSTA. F. de A. Trajetórias Tecnológicas como Objeto de Política de Conhecimento para a Amazônia: uma metodologia de delineamento. Revista Brasileira de Inovação, 8(1), jan./ jun. 2009.

CRAICE, C.; SOUZA, M. F. S. Entre minérios e rios: notas sobre urbanização, migração e consumo no sudeste do Pará. Anais do XV Encontro da Associação Nacional de Planejamento Urbano e Regional. Recife, 2013.

FURTADO, C. Economia do desenvolvimento. Rio de Janeiro: Centro Celso Furtado; Editora Contraponto, 2009.

HOMMA, A. K. O. Agricultura familiar na Amazônia: a modernização da agricultura itinerante. In: SOUSA, I. S. F. (Ed.). Agricultura familiar na dinâmica da pesquisa agropecuária. Brasília: Embrapa Informação Tecnológica, 2006.
Harley Silva é economista e historiador, doutorando em Economia pelo Cedeplar/ UFMG. E-mail: <harley@ cedeplar.ufmg.br>.

Sibelle Diniz é economista, doutoranda em Economia pelo Cedeplar/UFMG. E-mail: <sibelled@cedeplar.ufmg.br>.

Vanessa Ferreira é economista, assistente de pesquisa no Cedeplar/UFMG. E-mail: <vanessacf@cedeplar.ufmg.br>. 
HOMMA, A. K. O. Amazônia: como aproveitar os benefícios da destruição? Estudos Avançados, 19 (54), 2005.

INSTITUTO NACIONAL DE PESQUISAS ESPACIAIS. Projeto UrbisAmazônia: Qual a Natureza do Urbano na Amazônia Contemporânea? O Urbano Extensivo e os Circuitos da Economia: O Papel das Redes na Construção dos Lugares e na Configuração Multi-escala do Urbano Amazônico. Apontamentos para um Diálogo com as Políticas Públicas Climáticas e Ambientais para a Região. São José dos Campos: INPE, 2011.

INSTITUTO NACIONAL DE PESQUISAS ESPACIAIS. Projeto UrbisAmazônia: Qual a Natureza do Urbano na Amazônia Contemporânea? O Urbano Extensivo e os Circuitos da Economia: O Papel das Redes na Construção dos Lugares e na Configuração Multi-escala do Urbano Amazônico. $1^{o}$ Relatório de Acompanhamento de Projeto. Período:01/01/2012 a 30/09/2012. São José dos Campos: INPE, 2012.

JACOBS, J. The economy of cities. New York: Random House Inc., 1970.

LEFEBVRE, H. Espaço e politica. Belo Horizonte: Editora UFMG, 2008.

MONTE-MÓR, R. L. M. Urbanização extensiva e novas lógicas de povoamento: um olhar ambiental. In: SANTOS, M. et al. (Eds.). Território: globalização e fragmentação. São Paulo: Hucitec/Anpur, 1994.

RIBEIRO, D. O povo brasileiro: a formação e o sentido do Brasil. São Paulo: Companhia das Letras, 2006.

RISÉRIO, A. A cidade no Brasil. Rio de Janeiro: Editora 34, 2012.

RODRÍGUEZ, O. O estruturalismo latino-americano. Rio de Janeiro: Civilização Brasileira, 2009.

SANTOS, M. Da totalidade ao lugar. São Paulo: Edusp, 2008.

SANTOS, M. O espaço dividido: os dois circuitos da economia urbana dos países subdesenvolvidos. Rio de Janeiro: F. Alves, 1979.

SANTOS, M. O trabalho do geógrafo no terceiro mundo. São Paulo: Edusp, 2009.

A B S T R A C T Although the expansion offormal labormarket is a sustained trend in Brazil, occupation in the lower circuit of the economy is persistent and poorly understood. In Brazilian Amazon frontiers, informal, family and solidarity economy persists, in spite of large investments destinated to the upper circuit. This work investigates the current context of the southeast of Para, where the formal economy of some municipalities has grown at "Chinese rates", while alternative forms of economic integration incorporate the majority of the population.

K E Y W O R D S : popular economy; informal economy; lower circuit; Amazon frontier; southeast of Pará. 